\title{
Exposición de Eugenio Raúl Zaffaroni ante el Tribunal Supremo del Estado Plurinacional de Bolivia
}

\author{
Revista Derechos en Acción ISSN 2525-1678/ \\ e-ISSN 2525-1686 Año 5/№ 16 Invierno 2020 (21 \\ junio a 20 septiembre), 908-917 DOI: \\ https://doi.org/10.24215/25251678e449
}

Excmo. Señor Presidente del Tribunal Supremo de Justicia Excmas. Sras. Magistradas y Excmos. Sres. Magistrados.

Distinguidos colegas y público interviniente y participante de este Seminario

Sras. y Sres.

Ante todo, agradecemos profundamente el honor que nos dispensa el Excmo. Tribunal Supremo del Estado Plurinacional de Bolivia con la honrosa invitación a participar en este seminario.

Nos tomamos también la libertad de felicitar al Excmo. Tribunal por la iniciativa misma del Seminario, que es una clara demostración de preocupación frente a las cuestiones que plantean estos momentos difíciles para nuestra región y el mundo, especialmente para la magistratura encargada de la compleja y sagrada misión de ejercer el control jurisdiccional de constitucionalidad y de convencionalidad.

Esta preocupación de las máximas instancias jurisdiccionales frente a cualquier emergencia es la natural consecuencia de que, en todos los episodios de esa naturaleza, se reclaman medidas que limitan o suspenden derechos, precisamente en función de la necesidad que plantean.

Es comprensible la preocupación de todo juez ante cualquier emergencia, porque a nadie le pasa por alto que, a lo largo de 
toda la historia de nuestra cultura jurídica, desde la inquisición hasta el genocidio de la segunda guerra mundial y los posteriores, no hubo en el mundo ninguna aberración criminal del poder que no haya pretendido justificarse invocando la necesidad, sea en la forma de estado de necesidad o de legítima defensa.

Los crímenes de estado de todos los tiempos pretendieron ampararse en alguna de estas dos instituciones, siendo que, en definitiva, ambas son variables de la invocación de la necesidad, al punto que la doctrina alemana las deriva de una general teoría de la necesidad: Not, y de allí Notstand y Notwehr.

El derecho internacional de los DDHH, como todo el derecho en general, también se encuentra frente a la necesidad de tratar de establecer cuándo una limitación es jurídicamente admisible y cuándo debe rechazarse por configurar un abuso de poder del estado o un mero pretexto para cualquier otro objetivo.

Salvo en cuanto a la tortura y a la esclavitud, el derecho internacional de los DDHH reconoce que no hay derecho que no puede limitarse o suspenderse en razón de situaciones de necesidad.

Pero las emergencias, como su nombre lo indica, no suelen ser previsibles, y la pandemia es quizá el más paradigmático ejemplo de imprevisibilidad. Debido a eso, el "margen de apreciación" que los derechos humanos deben reconocer a cada estado frente a cada emergencia particular, no puede menos que ser amplio.

Para tratar de evitar o reducir la arbitrariedad, en las últimas décadas -a partir de la jurisprudencia del tribunal europeo-, se está difundiendo en la teoría jurídica la exigencia de que toda limitación en función de necesidad deba responder a una "necesidad social imperiosa".

Por otra parte, también se exige que los tribunales deban constatar el estándar mediante una comparación con los modelos de "sociedad democrática", es decir, verificar si la limitación, en iguales circunstancias, sería admisible en cualquier modelo de sociedad democrática. 
Pero estos tanteos jurisprudenciales son en el fondo derivaciones de la regla delimitadora general entre la necesidad justificante y la perversión de ésta como abuso o pretexto, que es el llamado "principio de proporcionalidad", que no es más que la traducción internacional de la regla de "racionalidad" de todo acto de gobierno, impuesta en el derecho interno por el principio republicano.

Este "principio de proporcionalidad" -que podría ser llamado de "racionalidad"- es la adaptación de una regla que desde siempre se aplica al estado de necesidad justificante en todo el derecho: el mal que se causa debe ser inferior al que se evita. Todos los códigos del mundo establecen esta regla para limitar la justificación por necesidad.

En consecuencia, tanto el derecho internacional como el interno de los estados republicanos, llegan al mismo principio que, aplicado al caso, rezaría: la limitación de derechos en razón de la pandemia, debe ser inferior a la lesión de derechos que tendría lugar de no procederse a esa limitación.

Conforme a esta regla se justifica la acción que limita o suspende derechos en razón de necesidad. ¿Pero a quién se justifica? A los estados, porque nunca debemos olvidar que en materia de DDHH los únicos sujetos de violaciones, es decir, los únicos "autores" de violaciones a DDHH, son los estados, no las personas que, en todo caso, podrán cometer delitos, pero no violaciones a DDHH.

Y los estados pueden cometer violaciones de DDHH por acción o por omisión.

En nuestra región se encuentra en curso una violación de DDHH por omisión, que es anterior a la pandemia y que ésta agrava ahora al extremo, que es la superpoblación de las cárceles, materia en la cual Bolivia está en una de las peores condiciones, con más del 300\% de concentración penal.

Conforme a los estándares internacionales, una pena o una prisión preventiva en esas condiciones, es una tortura o, por lo menos, un trato cruel, inhumana o degradante. 
En puridad jurídica, los jueces de todos los estados que registran superpoblación penal, entre los que, por supuesto, incluyo a la Argentina, se convierten en autores mediatos de tortura o de tratos crueles, inhumanos o degradantes.

Frente a esta situación, los estados continúan omitiendo toda solución, con lo cual siguen permitiendo que continúen acumulándose presos, sobre todo preventivos, en prisiones convertidas en campos de concentración.

Los estados de nuestra región han visto impasibles crecer el proceso de gran encarcelamiento de las últimas décadas, en una clara violación de DDHH por omisión.

Esta violación por omisión se continúa ahora, pese a la pandemia, sin hacer nada por disminuir el número de presos, sabiendo que cada presidio superpoblado es una bomba virósica, con lo que, a las condiciones aberrantes de detención, se suma en estos momentos una amenaza de muerte por infección, cuyo riesgo advirtieron desde la OMS hasta el Papa, pasando por el subcomité contra la tortura de la ONU, la relatora de DDHH y el relator de independencia judicial de la ONU, el comité internacional de la Cruz Roja, la Comisión IDH, la Corte IDH, etc.

Pero también, durante la pandemia, los estados pueden violar DDHH por acción, cuando las limitaciones a derechos que imponen sean más lesivas que las consecuencias que evitan, o sea, cuando exceden el límite que impone la necesidad justificante, conforme al señalado principio de racionalidad o de proporcionalidad.

Nos permitimos insistir en que la observancia de este principio se impone no sólo por vía del derecho internacional, aunque sería suficiente con eso, dada la teoría dominante en el mundo actual del "derecho único" o "tesis monista", sino que también estamos obligados a respetarla en nuestros estados, porque tenemos formas de gobierno republicanas (en el caso del Estado Plurinacional de Bolivia expresamente el artículo $11^{\circ}$ constitucional). 
Por ende, no es racional conforme al derecho interno, ni proporcional en razón del derecho internacional de los $\mathrm{DDHH}$, que en razón de la pandemia se determine una limitación de derechos más lesiva que la que se pretenda evitar.

En este sentido, somos conscientes de que el problema más serio que se presenta ahora en Bolivia, es la posibilidad de una nueva postergación de las elecciones generales. en razón de la pandemia. Por tal motivo, nos hemos de centrar seguidamente en este problema.

Ante todo, siguiendo el orden de los principios y reglas a los que nos referimos antes, creemos que una nueva postergación de elecciones no superaría el test que se va expandiendo sobre la "necesidad social imperiosa" de la medida, habida cuenta de los medios técnicos hoy disponibles para llevar a cabo una elección en estas condiciones y sin inconvenientes ni riesgos insalvables.

Tampoco creemos que pudiese superar la regla comparativa impuesta por el modelo de "sociedad democrática", porque no se ha registrado en ningún otro estado una postergación sucesiva de elecciones con motivo de la pandemia y, además, sería casi inconcebible que alguna democracia estable y seria lo hiciese.

Pero, tal como dijimos antes, estas reglas no son otra cosa que derivaciones particulares del general principio de racionalidad o proporcionalidad que rige tanto internacional como internamente, cualquiera sea la tesis -monista o dualista- que se sostenga respecto al derecho internacional y nacional.

La aplicación del mencionado principio requiere, pues, una ponderación de "males", porque toda limitación de derechos, sea o no racional, nunca deja de ser un mal. Por tal razón debe indagarse en cada caso cuál es el mal mayor.

Descartado que la pandemia impida realmente la celebración de los comicios porque, como señalamos antes, la tecnología actual lo permite, aunque se deban superar algunas dificultades menores, tampoco vemos serios impedimentos para 
el desarrollo de las campañas electorales, pues con los medios de comunicación repartidos democráticamente, la comunicación de los partidos con la población no se altera.

En la actualidad, las campañas electorales no requieren de concentraciones masivas, ni en Bolivia ni en ningún otro país.

En otro orden de cosas, tampoco creemos que la postergación de los comicios tenga algún efecto controlador sobre la difusión de la pandemia, puesto que la asistencia a los centros de votación se podría programar racionalmente para impedir riesgos, que no serían mayores que los de la circulación que, por otra parte, ya se está produciendo en casi todos nuestros países.

En síntesis: los riesgos de una lesión a derechos con motivo de la elección -y en especial del derecho a la vida- son bastante remotos.

Cabe advertir en esto que, cuando de ponderar males se trata, no se lo debe hacer en abstracto, como sería "derecho de votar" frente a "derecho a la vida", sino que debe valorarse en concreto, habida cuenta de la inmediatez o proximidad y lejanía de los males.

Un mal gravísimo en abstracto, como la lesión el derecho a la vida, no lo es en concreto, porque resulta remoto y poco probable, en tanto que el primero, es decir, la postergación de la elección, es inmediato y seguro.

Por otro lado, corresponde ponderar la gravedad de los efectos de los males concretos, inmediatos y seguros, que resultarían de una nueva postergación de las elecciones.

A este respecto, debemos pedir que lo que a continuación diremos no sea tomado como un acto de denuncia, porque no pretendemos este efecto que, obviamente, no sería esta la ocasión ni lo adecuado. Simplemente pretendemos evaluar en contexto los daños emergentes, basándonos en datos verificables, sin perjuicio de la calificación, que es otra discusión que en este momento no viene al caso.

En principio, es verificable que la situación institucional de Bolivia es anómala. Ha habido un acto de fuerza, de cuya calificación 
prescindimos, pero cuya existencia es innegable. Con posterioridad se han sucedido hechos discutidos, pero lo verificable es que al respecto circulan denuncias y noticias por todo el mundo.

Pero únicamente "ad argumentandum" no los damos por ciertos, aunque algunos lo son claramente, como la permanencia de siete personas en asilo diplomático, a las que se les niega el salvoconducto de salida, en forma violatoria de las reglas más elementales del derecho de gentes.

Más allá de la verdad respecto del contenido de denuncias y noticias en particular, lo verificable es que éstas circulan por el mundo y se abarrotan los organismos internacionales con denuncias y algunos de ellos, ciertamente importantes, formulan advertencias y recomendaciones, como la Comisión IDH y recientemente la Relatoría de DDHH de la ONU. Incluso siete senadores demócratas norteamericanos se han hecho eco de estas denuncias y noticias.

No es menos cierto que en el último tiempo se procesó a muchos candidatos y se corre el riesgo de que un candidato a presidente pueda ser inhabilitado antes de los comicios.

Tomemos el contexto sólo con estos elementos, insisto que "ad argumentandum", o sea, sin dar por cierto el contenido de las noticias y de las denuncias, sino limitándonos a verificar su existencia.

Esa mera existencia da lugar a la sospecha, lo que ya de por sí constituye un mal enorme, porque pone en entredicho ante el mundo la democracia en Bolivia y la propia legalidad jurídica de su Estado.

Así, por ejemplo, sea o no cierto, en este contexto no se puede descartar la versión o la sospecha de que los procesos a candidatos tengan por objeto la proscripción indirecta de una fuerza política. Los procesos existen, y eso hace inevitable la sospecha en este contexto.

Con ese motivo, circula por el mundo un pesado manto de duda, en razón de que este procedimiento se ha vuelto frecuente y se reitera en otros países en el último tiempo. 
Ahora, eso que sucede en otros países, se lo llama "lawfare", pero es más viejo que todos nosotros: se lo usó cuando se procesó en mi país al presidente Yrigoyen por la dictadura de 1930, o al presidente Perón por la dictadura de 1955, cuando la primera proscribió al radicalismo y la segunda al justicialismo, proscripción que nos duró diez y siete años, y que nos dejó una herida que acabó décadas después con la tragedia de 30.000 desaparecidos. No es ninguna novedad. Y por eso, precisamente, cuando se procesan a candidatos en cualquier país de nuestra región, inmediatamente se sospecha.

Si a eso se suma, el acto de fuerza -que ha existido- las otras noticias, la violación del derecho de asilo y, ahora una nueva postergación de elecciones, la sospecha se incrementa al máximo y, la imagen internacional del país se deteriora mucho más.

El mal que esto implica es un daño a Bolivia como nación en el concierto de las naciones de la región y del mundo. Por decirlo más claramente: no se debe tolerar que Bolivia ni ningún otro estado pueda ser considerado un estado de segunda categoría en el mundo.

Eso lo hemos vivido los argentinos muchos años, cuando no podíamos juzgar los crímenes de lesa humanidad cometidos en nuestro territorio. Pasamos a ser un estado de segunda categoría e incluso, en función del principio universal, otros estados asumían la función jurisdiccional sobre nuestros ciudadanos. Así fue hasta que recuperamos el ejercicio de nuestra jurisdicción y reparamos nuestra imagen ante el mundo.

No deseamos que los bolivianos sientan lo mismo, porque es muy doloroso.

Los hechos del pasado inmediato en Bolivia ya pasaron, no podemos hacer que no hayan pasado. Es imposible revertir la película del tiempo.

Por eso, ahora se trata de mirar al futuro y ser proposicionales. Las heridas están. ¿Cómo curarlas, cicatrizarlas y, de ser posible, borrar las cicatrices? Esa es la pregunta actual, dividida 
en tres momentos: curación, cicatrización y cancelación de la huella de la lesión.

Sabemos que los hechos del pasado pueden ser motivo de venganzas futuras, no somos ingenuos. Cuando los seres humanos sentimos deseos de la venganza, es porque nos es imposible hacer que lo que pasó no haya pasado. La venganza es contra el tiempo, decía Nietzsche.

Pero también sabemos que hay formas de evitar las tentaciones vindicativas: los crímenes contra la humanidad no son amnistiables, pero los delitos políticos se pueden amnistiar, los procesos pueden anularse, las sentencias revisarse, las penas indultarse, etc.

No olvidemos que la política es en gran medida un arte de negociación y todo conflicto, antes de que adquiera mayores proporciones, puede resolverse por el camino de la pacificación de los espíritus y de la obstaculización de cualquier tentación vindicativa por vía de negociación.

Pero el primer paso, la primera curación de la herida del pasado inmediato, lo más elemental para la eliminación de las sospechas y para la reparación de la imagen internacional de la Nación Boliviana, no puede ser otra que la celebración de elecciones transparentes y sin proscripciones, arbitrariedades ni fraudes, ni manifiestos ni encubiertos.

Esa es la primera curación, la más urgente. A partir de allí nadie podrá imputarle a Bolivia ninguna inferioridad ni usar eso como pretexto en ninguna negociación financiera o económica. Con eso será indiscutible la recuperación de la dignidad nacional ante el mundo.

El segundo paso, o sea, la cicatrización de las heridas del pasado reciente, no puede ser otro que una sana y sincera negociación conforme al mejor arte de la política. Bolivia no puede quedar dividida, no puede debilitar su sentimiento nacional con divisiones insalvables, no puede comprometer el sentimiento de pertenencia, de comunidad nacional en el buen sentido de la palabra. 
El tercer paso, borrar la huella de la cicatriz, es una tarea más lenta, pero ya vendrá.

En la ponderación de males, pocas dudas nos caben acerca de que la postergación de la elección en esta emergencia y en este contexto, provocaría un mal mucho mayor que la amenaza remota que se pretendería evitar con esa medida.

En las antedichas circunstancias, $\tan$ enorme es la diferencia en la ponderación de los males, que la propia postergación de las elecciones generales no haría más de reconfirmar todas las sospechas, a un grado tal que ya pasarían a convertirse en indicios y en pruebas directas.

Este Excmo. Tribunal Supremo tiene en sus manos la decisión.

Delicadísma e histórica tarea a cargo de sus Excmas. Juezas y Excmos. Jueces.

Somos consciente de las dificultades, no nos pasan por alto, pero también de que el mundo los estará observando y, por difícil que sea la decisión, también tendrán la magnífica oportunidad de que desde nuestra sufrida y problemática región un tribunal muestre una lección de prudencia y sabiduría al mundo.

En manos de este Tribunal está la dignidad misma de vuestra Nación frente al mundo.

Sólo las juezas y jueces de este alto Tribunal tienen la posibilidad de apartar toda duda, de restañar los males, de restablecer la democracia plena en Bolivia y dignificar la Nación frente a la región y al mundo.

Sólo me queda desear que Dios les ilumine la inteligencia y les dé fuerzas a sus espíritus. 